\title{
Stroke and Patent Foramen Ovale in Young Individuals
}

\author{
Bartlomiej Piechowski-Jozwiak $^{a}$ Julien Bogousslavsky ${ }^{b}$ \\ ${ }^{a}$ Clinical Lead Hyper Acute Stroke Unit, Princess Royal University Hospital, Orpington, UK; ${ }^{b}$ Center for \\ Brain and Nervous System Diseases (Neurocenter), Genolier Swiss Medical Network, Clinique Valmont, \\ Glion/Montreux, Switzerland
}

\section{Key Words}

Patent foramen ovale $\cdot$ Right-to-left shunting $\cdot$ Ischemic stroke $\cdot$ Atrial septal aneurysm $\cdot$ Surgical closure $\cdot$

Antiplatelets $\cdot$ Anticoagulants

\begin{abstract}
The importance of patent foramen ovale (PFO) has long been discussed in the literature in relation to different coexisting medical conditions. Many researchers focused on the occurrence of PFO in ischemic stroke patients, especially in the subgroup of young patients with a recurrent event. Unfortunately, before establishing a clear significance of PFO and right-to-left shunting (RLS) in pathogenesis of cerebrovascular disorders, multiple interventional trials have been launched, aimed at PFO closure in heterogeneous populations of patients. Moreover, some closure devices were granted at least partial approval by regulatory agencies for this indication. There is a need for large and unbiased epidemiological studies assessing the role of RLS through the PFO in ischemic stroke. All patients with recurrent ischemic events and PFO should be assessed by multidisciplinary teams, including a stroke neurologist, and all potential and rare causes of stroke should be considered before any decision for closure is made.

Copyright $\odot 2012$ S. Karger AG, Basel
\end{abstract}

\section{Embryological and Epidemiological Background of Patent Foramen Ovale}

Patent foramen ovale (PFO) is a residual element of the fetal circulation. Before explaining the pathophysiology of right-to-left shunting (RLS) through the PFO, it is crucial to concentrate on several steps of fetal heart development. First, there is the formation of a primary myocardial tube followed by the myocardial tube looping and formation of cardiac chambers and major vascular trunks [1]. Division of atria into two chambers involves several steps, and in the final stage the two overlapping structures namely septum primum and septum secundum merge and fuse to form the interatrial septum [2]. During the fetal development, blood bypasses from the right atrium directly into the left atrium through the foramen ovale. In the human fetus, the venous hemodynamics privileges the flow from the ductus venosus over the flow from the inferior vena cava in passing through the foramen ovale as the umbilical cord flow is stronger $[3,4]$. The strong blood flow with a velocity up to $85 \mathrm{~cm} / \mathrm{s}$ distends the valve of the foramen ovale and forces the blood into the left atrium [3]. Volume of blood that crosses the foramen ovale equals $34 \%$ of cardiac output at 20 weeks, and $18 \%$ at 30 weeks of pregnancy [5]. At birth, the most im-

\section{KARGER}

Fax +4161306 1234

E-Mail karger@karger.ch

www.karger.com
(C) 2012 S. Karger AG, Basel

0014-3022/13/0692-0108\$38.00/0

Accessible online at:

www.karger.com/ene
Bartlomiej Piechowski-Jozwiak

Clinical Lead Hyper Acute Stroke Unit

Princess Royal University Hospital, Farnborough Common

Orpington BR6 8ND (UK)

E-Mail bartlomiejpj@gmail.com 
portant pressure changes happen as the drop of blood pressure in the right heart and opening of pulmonary blood vessels reverse the interatrial pressure gradient. As a consequence of these pressure changes, a firm fusion of septum primum and secundum is completed by the age of 2 years [6]. However, in an important percentage of otherwise normal individuals, the closure is incomplete resulting in the patency of the foramen ovale.

Pathological case series are relatively unbiased, but are still not comparable with proper epidemiological assessment of the prevalence of a condition. There are two milestone autopsy studies on the frequency of PFO conducted in a general population. The first one consisted of 1,100 autopsies. Results of this study showed that the frequency of PFO depended on its size. The smaller PFO defined as $2-5 \mathrm{~mm}$ in diameter was found in $29 \%$ of cases. The larger PFO defined as $6-10 \mathrm{~mm}$ in diameter was found in $6 \%$ of autopsied cases [7]. The second study was based on 965 autopsies. The overall incidence of PFO was $27.3 \%$. However, an interesting finding of a progressive decline of $\mathrm{PFO}$ frequency from $34.3 \%$ during the first three decades of life to $20.2 \%$ during the 9 th and 10 th decades was observed. Moreover, the diameter of the foramen ovale varied from 1 to $19 \mathrm{~mm}$, but in the great majority of cases it ranged from 1 to $10 \mathrm{~mm}$ in diameter. What is really difficult to interpret is the finding that, as the frequency of PFO declined with increasing age, an increase in diameter from a mean of $3.4 \mathrm{~mm}$ in the first decade to $5.8 \mathrm{~mm}$ in the 10th decade of life was observed. The potential explanation for these changes, as mentioned in the article, could be the fact that smaller PFOs might have spontaneously closed. This would explain the fact that larger PFOs remained opened until the patients' death [8]. However, autopsy studies are not longitudinal, and we cannot base any pathophysiological assumptions based on these results.

There were also a few in vivo studies on the PFO occurrence based on contrast transesophageal echocardiography (TEE). Fisher et al. [9] showed the presence of PFO in $9.2 \%$ of 1,000 patients referred for a diagnostic TEE. Of note is the fact that there was a selection bias in this study as more than half of these patients were suspected of having had a cardioembolic stroke. In this cohort, the incidence of PFO in patients in their fifth decade was greater than in those in their eighth decade (12.96 vs. $6.15 \%, \mathrm{p}=0.03)$. Meissner et al. [10] demonstrated the presence of PFO in $25.6 \%$ of studied individuals in a random general population $(n=588)$ over the age of 45 years undergoing TEE. Results of both pathological and TTEbased studies cannot however be considered as true epidemiological data on the prevalence of the condition.

\section{Coexisting Atrial Anatomical Abnormalities: Atrial Septal Aneurysm and Chiari's Network}

There are other anatomical variants in the atrial anatomy accompanying PFO. One of them is atrial septal aneurysm (ASA). ASA can be diagnosed with the TEE based on the following criteria [11]: (1) diameter of the base of the aneurysmatic portion of the interatrial septum of more than $15 \mathrm{~mm}$; (2) protrusion of interatrial septum or a part of it beyond its plane of more than $15 \mathrm{~mm}$; (3) phasic excursion of the interatrial septum during the cardiorespiratory cycle of more than $15 \mathrm{~mm}$ in amplitude.

In a case-control study conducted by Agmon et al. [12], the frequency of ASA was $7.9 \%$ in patients with a history of cerebral ischemic events in comparison to $2.2 \%$ in matched controls (OR 3.65; 95\% CI: 1.64-8.13). There was another interesting finding in this study as $56 \%$ of subjects with ASA had RLS through a PFO. Based on these findings, the authors calculated the odds for the presence of ASA predicting the presence of PFO (4.57; 95\% CI: 2.18-9.57). Results of this study should be interpreted with caution however considering its case-control design.

The other atrial abnormalities are variants of the Eustachain valve, described for the first time by Eustachius in 1563. Three hundred years later, the Chiari's network was described $[13,14]$. The Chiari network results from the incomplete resorption of septum spurium and the right valve of sinus venosus. It is built out of fibers attached to the upper wall of the right atrium and/or interventricular septum. According to the original Chiari's work, the frequency of Chiari's network in unselected autopsy series is around $2-3 \%$. In TEE series, the frequency of Chiari's network is similar (2\%). There is an interesting finding that Chiari's network coexists with PFO in $83 \%$ of cases and with ASA in $21.2 \%$ of cases [15]. There is a potential pathophysiological explanation for the coexistence of PFO and Chiari's network. The latter may more or less continuously float the blood from the inferior cava against the septum primum, thereby preventing fusion of the 2 septa. The same may be true for the coexistence of ASA and PFO. Thus, both of these anatomical abnormalities may be a cause of $\mathrm{PFO}$ occurrence rather than just bystanders. There are a few case reports of Chiari's network having had a causative role as the source of embolic material that led to the occurrence of an ischemic stroke in a mechanism of paradoxical embolization [16]. In preselected populations, Chiari's network was shown to be more prevalent in cryptogenic stroke patients when compared to controls (4.6 vs. $0.5 \%)[17,18]$. 


\section{PFO and Coexisting Conditions}

The PFO with or without coexistent ASA has been linked to multiple central nervous system disorders such as first-ever ischemic stroke in young patients $[19,20]$, cryptogenic stroke $[21,22]$ and cerebral decompression sickness in scuba divers $[23,24]$. The presence of PFO was also studied in hypobaric decompression sickness in altitude flyers and astronauts [25], high-altitude pulmonary edema [26], platypnea-orthodeoxia syndrome [27], brain abscess [28], transient global amnesia [29], spinal cord ischemia [30], and systemic embolization in solid organs as well as in upper and lower extremities and in migraine [31-35]. All of these studies are at best case series reports, and no cause-effect relationship can be established based on them.

Some authors do not confirm the association between isolated PFO and increased risk of ischemic stroke [36] or recurrent stroke $[22,37]$. There is no clear correlation between the size of the PFO and the degree of right-to-left cardiac shunt and occurrence of stroke [22, 37]. However, some authors demonstrated that the presence of a large PFO and high degree of right-to-left cardiac shunt (RLS) could increase the risk of cryptogenic stroke [37-40], recurrent stroke $[41,42]$ and the number of silent ischemic brain lesions in divers [43].

\section{Features of Ischemic Stroke in Patients with PFO}

There are a few reports addressing the presentation and course of an ischemic stroke in patients with a PFO. In general terms, one can say that patients with an ischemic stroke and a PFO are younger and have less traditional cardiovascular risk factors. Prognosis of stroke recovery seems to be better as $63.3 \%$ of patients with a PFO achieve a modified Rankin Scale score of 0-1 (good clinical outcome) in comparison to $52.5 \%$ of those without a PFO. Apparently, there is no predilection for vascular territory involvement either [36]. In addition to this, neuroimaging features of an embolic infarction are not consistently being found in those with a PFO and ischemic stroke $[36,40]$.

\section{Paradoxical Embolism and RLS}

Currently, the potential role of the PFO in pathogenesis of an ischemic stroke is based on the paradoxical embolism. There are well-established clinical criteria allow- ing for a diagnosis of possible cerebral paradoxical embolism. These criteria were coined in the 1950s, and they do not contain documentation of the actual passage of the embolic material through the PFO. These criteria are the following [44]: (1) proven arterial (cerebral) embolism; (2) no embolic material in the left heart; (3) venous thrombosis/pulmonary embolism; (4) intracardiac communication permitting an RLS.

However, proving paradoxical embolism even in a situation when all these criteria are met is difficult. In addition to this, several authors do not consider mechanical passage of embolic material through the interatrial septum as the only explanation for ischemic stroke in patients with the presence of a PFO. One potential mechanism is smooth muscle dysfunction. There is a recent paper by Zicari et al. [45] in which the authors studied 24 patients with CADASIL, and they found that $47 \%$ of these patients had RLS, which is a double value in comparison to the non-stroke population. This comparison cannot be made directly as this study was not designed to test for this effect. The potential mechanism linking CADASIL and PFO could be that of abnormal Notch signaling that may lead to gradual degeneration of vascular smooth muscle cells, thus leading to arterial wall thickening and consequently to luminal narrowing and small vessel supply infarcts. Cardiac involvement can be explained by abnormal development of endocardial cushion as Notch 3 may have a crucial role in the morphogenesis of heart chambers and especially cardiac septa [46].

In addition to this, metabolic shunting through the PFO can be considered as one of the mechanisms responsible for stroke occurrence in RLS. Venous blood shunting was demonstrated in patients with a PFO as they were found to have oxygen desaturation determined with ear oximetry [47]. However, others did not confirm these results with arterial blood analysis [48]. Metabolic shunting can be explained by bypassing the lung filter which metabolizes many substances such as biogenic amines such as serotonin [49]. In cases of persistent RLS or during Valsalva maneuver, part of these vasoactive substances could bypass pulmonary filter, thus causing 'metabolic RLS', and directly enter the arterial circulation activating platelets, or exerting their action on cerebral vasculature. This hypothesis was also discussed in the pathogenesis of migraine [50]. There was one study that demonstrated a correlation between the degree of RLS and the arterial levels of norepinephrine and serotonin [51]. 
Table 1. Occurrence of PFO, ASA or both in ischemic stroke patients versus non-stroke controls

\begin{tabular}{lllr}
\hline & PFO & ASA & \multicolumn{1}{c}{ PFO+ASA } \\
\hline All age groups $^{1}$ & $1.83(1.25-2.66)$ & $2.35(1.46-3.77)$ & $4.96(2.37-10.39)$ \\
Below 55 years $^{2}$ & $3.10(2.29-4.21)$ & $6.14(2.47-15.22)$ & $15.59(2.83-85.87)$ \\
Above 55 years $^{2}$ & $1.27(0.80-2.01)$ & $3.43(1.89-6.22)$ & $5.09(1.25-20.74)$ \\
\hline
\end{tabular}

Figures indicate OR (95\% CI).

${ }^{1}$ Random effect. ${ }^{2}$ Fixed effect.

Table 2. Comparison of all patients with cryptogenic stroke versus those with known etiology of stroke

\begin{tabular}{llll}
\hline & PFO & ASA & PFO+ASA \\
\hline All age groups $^{1}$ & $3.16(2.30-4.35)$ & $3.65(1.34-9.97)$ & $23.26(5.24-103.20)$ \\
Below 55 years $^{2}$ & $6.00(3.72-9.68)$ & NA & NA \\
Above 55 years $^{2}$ & $2.26(0.96-5.31)$ & NA & NA \\
\hline
\end{tabular}

Figures indicate OR (95\% CI).

${ }^{1}$ Random effect. ${ }^{2}$ Fixed effect.

Table 3. Comparison of cryptogenic stroke patients versus non-stroke controls

\begin{tabular}{llcl}
\hline & PFO & ASA & PFO+ASA \\
\hline All age groups $^{1}$ & $2.95(2.01-4.33)$ & $4.12(2.72-6.26)$ & $23.93(3.09-185.42)$ \\
Below 55 years & $5.01(3.24-7.75)$ & $19.17(2.46-149.47)$ & $23.93(3.09-185.42)$ \\
\hline
\end{tabular}

Figures indicate OR (95\% CI).

${ }^{1}$ Random effect. ${ }^{2}$ Fixed effect.

\section{Epidemiology of Ischemic Stroke in Young Adults with PFO}

As mentioned at the beginning of this paper, there are no large-scale prospective epidemiological studies focused on the occurrence of ischemic stroke in patients with right-to-left shunt through the PFO. There are a few case-control studies, which were compared together in one meta-analysis [20]. This meta-analysis yielded very important results that may be divided into three major groups, the first being the occurrence of PFO, ASA or both in ischemic stroke patients vs. non-stroke controls. Second is the occurrence of PFO, ASA or both in cryptogenic stroke patients versus patients with known etiology of stroke and third is the occurrence of the above-mentioned atrial abnormalities in cryptogenic stroke patients versus non-stroke controls (tables 1-3).
Results of this meta-analysis need to be interpreted with caution as studies included in it were observational and of various sizes and the total numbers for each comparison were not at the desirable level, thus the confidence intervals in the majority of comparisons were very wide (e.g. odds for PFO+ASA in young cryptogenic patients vs. non-stroke controls equaling 23.93 with $95 \% \mathrm{CI}$ : 3.09-185.42). In addition to this, the data on the odds for $\mathrm{PFO+ASA}$ in cryptogenic stroke group versus non-stroke controls came from a single study. There was also a diagnostic bias in studies that used transthoracic rather than transesophageal echo as the former underestimates the prevalence of ASA. In summary, we can say that this meta-analysis showed a significant association between PFO, ASA and occurrence of first-ever ischemic stroke in patients below 55 years of age [20]. 
The other important issue is stroke recurrence in patients with a PFO and or ASA. Homma et al. [37] demonstrated that there is no difference in the risk of stroke recurrence and death within 2 years of observation in cryptogenic stroke patients on medical treatment with PFO alone or PFO+ASA (14.8 vs. $15.4 \%$, respectively). Mas et al. [22] demonstrated an increased risk of recurrence of stroke in cryptogenic stroke patients who have both $\mathrm{PFO}+\mathrm{ASA}$ as the 4-year stroke risk in these patients was $15.2 \%$ when compared to $2.3 \%$ in those with PFO alone and $4.2 \%$ in patients without $\mathrm{PFO}$ and ASA.

Bogousslavsky et al. [52] conducted a prospective follow-up of patients below the age of $60(\mathrm{n}=140)$ who presented with ischemic stroke $(\mathrm{n}=118 ; 84 \%)$ or transient ischemic attack $(n=22 ; 16 \%)$. All of these patients had confirmed PFO, and a quarter of them had ASA. These patients were followed for a mean of 3 years. There were just a few events of stroke or death (2.4\% per year) and stroke alone of $1.9 \%$ per year. These results are even more interesting if one takes into account the severity of initial stroke in this population as half of studied patients suffered from a disabling stroke.

Serena at al. [53] prospectively studied the risk of stroke recurrence in patients with cryptogenic stroke. Four hundred and eighty-six patients were recruited into the study and followed for a mean of $729 \pm 411$ days. In $200(41.2 \%)$, a massive right-to-left shunt was found. Overall, the rate of recurrent stroke was low in the whole group (5.8\%), and did not differ in patients with massive right-to-left shunt, non-massive right-to-left shunt and in those without the shunt in the younger group (3.4 vs. 2.3 vs. $4.5 \% ; \mathrm{p}=0.75)$ and in the whole cohort ( 5.0 vs. 6.2 vs. $6.3 \% ; \mathrm{p}=0.58$ ). After adjusting for treatment, there was no association between massive RLS and stroke recurrence with an odds ratio of 1.44 (95\% CI: 0.46-4.48; $\mathrm{p}=$ 0.53 ). In addition to this, ASA presence had no influence on stroke recurrence rate.

In a very recent paper, Fisher et al. [54] studied the long-term risk of stroke recurrence in 86 patients with a PFO-related stroke. These patients constituted $89 \%$ of the original cohort. The mean follow-up period was 15.4 years (range 11.2-25.9 years). These patients were offered secondary stroke prevention at the discretion of the treating physician. In total, there were 13 recurrent events (15\%) that included 7 transient ischemic attacks, 5 strokes and one peripheral embolism. According to the authors, the risk of recurrence was not related to secondary prevention strategy or coexistence of ASA and PFO size. These results are interesting as they suggest that recurrent embolic events can occur during a long follow-up irrespective of medical therapy, but due to this study's sample and its design, results should be interpreted with caution. However, other authors did not find statistical evidence for the role of PFO in stroke recurrence.

\section{Recurrent Stroke Prevention}

\section{Medical Management}

The quest for the appropriate medical management of stroke patients with a PFO has been ongoing for almost two decades. Mas et al. [22] in their pivotal study found that when on acetylsalicylic acid, stroke recurrence rates over a 4 -year observation period were $2.3 \%$ in $\mathrm{PFO}$ and $15.2 \%$ in PFO+ASA groups. However, this was not an interventional study comparing different treatment modalities.

The Patent Foramen Ovale in Cryptogenic Stroke Study (PICSS) was developed in cooperation with the Warfarin-Aspirin Recurrent Stroke Study [37, 55]. The latter was designed to compare aspirin and warfarin use in prevention of stroke recurrence in non-cardioembolic stroke survivors [55]. PICSS was a multicenter study in which patients were assigned to warfarin or aspirin. There were 630 patients enrolled, including 203 (33.8\%) with a PFO. Within the entire PICSS cohort among patients with a PFO, there were $16.5 \%$ events (recurrent stroke or death) in those on warfarin versus $13.2 \%$ in those on aspirin (HR 1.29; 95\% CI: $0.63-2.64 ; \mathrm{p}=\mathrm{NS}$ ). In patients without $\mathrm{PFO}$, the rates were 13.4 versus $17.4 \%$, respectively (HR $0.80 ; 0.49-1.33 ; \mathrm{p}=\mathrm{NS}$ ). In the cryptogenic cohort among patients with a PFO, the rates were 9.5\% on warfarin versus $17.9 \%$ on aspirin (HR $0.52 ; 0.16-$ $1.67 ; \mathrm{p}=\mathrm{NS}$ ). In the subgroup without a PFO, those on warfarin had a recurrence rate of $8.3 \%$ versus $16.3 \%$ for those on aspirin (HR 0.50; 0.19-1.31; p = NS). Results of PICSS demonstrated no difference between warfarin and aspirin in recurrent stroke prevention in patients with a PFO and non-cryptogenic stroke and cryptogenic stroke. Of note is the rate of hemorrhagic complications. The rates of minor bleeds were statistically significantly higher in those on warfarin when compared to aspirin (23 vs. 9 per 100 patient-years; $p<0.001)$, and the rates of major hemorrhages were no different (1.9 vs. 1.8 per 100 patientyears, respectively) [37].

In the study of Serena et al. [53], medical management was at the discretion of the treating neurologist. Antiplatelet medications were used as secondary stroke prevention in $79 \%$ of patients, and $21 \%$ received anticoagulation therapy with acenocoumarol with a target INR of 
$2-3$. There were no statistically significant differences between these two groups, and the rates of recurrence were 3.5 versus $3.2 \%$ in the younger population (antiplatelet vs. anticoagulants; $p=0.94$ ) and 6.6 versus $1.6 \%$, respectively, in the whole cohort $(p=0.18)$. Due to the study design, the effect of different treatment modalities cannot be used to make any therapeutic decisions.

In a recent systematic review and meta-analysis of medical management of patients with PFO and with a history of cryptogenic ischemic stroke or transient ischemic attacks, Almekhlafi et al. [56] included 15 trials that were published up to the year 2008. A pooled relative risk for recurrent cerebral ischemic event (stroke or transient ischemic attack) in patients with PFO when compared to those without was 1.1 (95\% CI: 0.8-1.5) and for ischemic stroke only it was $0.8(0.5-1.3)$; both were not statistically significant. There was no superiority of different medical management strategies demonstrated.

\section{PFO Closure}

\section{Surgical Closure}

In parallel to research being conducted on medical interventions in stroke prevention in patients with a $\mathrm{PFO}$, there have been series of studies devoted to physical closure of a PFO and elimination of RLS. We need to remember that all these trials were based on the assumption that RLS through a PFO may be responsible for the occurrence of the recurrent ischemic stroke. Initial studies were based on the surgical PFO closure, and the more modern ones used various devices delivered via the intravascular route.

One of the first surgical closure studies was performed in Lausanne by Ruchat et al. [57] (surgery) and Devuyst et al. [58] (neurology). There were 32 patients included in this study based on their young age (below 60 years; mean age 38 years). The eligibility criteria consisted of those considered to have a high risk of stroke recurrence (at least two of the listed), a history of Valsalva strain before stroke $(\mathrm{n}=11)$, multiple clinical ischemic events $(n=13)$, multiple infarcts on brain magnetic resonance imaging $(\mathrm{n}=15)$, presence of an ASA $(\mathrm{n}=16)$ or large left-to-right shunting (defined as more than 50 microbubbles as detected with contrast TEE; $n=12$ ). All patients had direct suture of the PFO under cardiopulmonary bypass. There were no major general periprocedural complications including homologous blood transfusion, neurological, cardiac or renal complications. Patients were followed for more than $600 \mathrm{pa}-$ tient-months (mean of 2 years). During the follow-up period, there were no recurrent ischemic events, and of even greater importance there was no silent new brain lesions detected on the brain magnetic resonance imaging. There were only two residual right-to-left shunts detected by TEE and transcranial Doppler. The residual shunts were related to surgical procedure as these $2 \mathrm{pa}-$ tients had single but not double continuous suture. None of these patients was put on any antithrombotics during the follow-up period $[57,58]$.

Homma et al. [59] studied a group of 28 cryptogenic stroke patients with a PFO diagnosed with TEE. All these patients either refused or could not take oral anticoagulants. All were treated with open thoracotomy with cardiopulmonary bypass and direct suture without the use of patch material. There were no surgical complications. However, after a mean follow-up period of 19 months, 4 patients experienced ischemic complications including one stroke and 3 transient ischemic attacks. The actuarial rate of recurrence was calculated at a level of $19.5 \%$ (95\% CI: 2.2-36.8) after 13 months of follow-up. Of note is the fact that recurrences were observed only in patients older than 45 years. Thus, the recurrence rate was $0 \%$ in the younger group and 35\% in the older group. The relative risk of recurrence rose with one decade of age by 2.76 (95\% CI: 1.07-7.16).

Another group studying surgical PFO closure that was led by Dearani et al. [60]. This was a retrospective study of 91 patients with one or more cerebrovascular events; mean age of the studied population was $44.2 \pm$ 12.2 years. There were 59 patients with stroke and 32 with transient ischemic attacks. As far as risk factors for paradoxical embolism are concerned, 15 patients had Valsalva-like maneuver before an ischemic event, and 10 patients had thrombophilia. Surgery was performed with extracorporeal circulation and involved direct suture in 82 patients and patch closure in 9. Periprocedural complications consisted of transient atrial fibrillation $(n=11)$, pericardiac effusion treated with drainage $(n=$ 4), exploration for bleeding $(n=3)$ and surgical wound infection in one case. After a mean follow-up of 2.0 years, there were no ischemic strokes and 8 patients had had transient ischemic attacks including one related to temporal arteritis. Only 2 out of 8 transient ischemic attacks were different from the initial event including one patient with gait disturbance (initially hemiparesis) and confusion with stereotactic spells (initially aphasia with hemiparesis) [60].

Orgera et al. [61] performed a meta-analysis comparing medical management including antiplatelet treatment and oral anticoagulants with surgical PFO closure in prevention of recurrent cerebral ischemic events. This 
analysis included studies published between 1966 and 1999; thus, no device closure trials were included. Overall warfarin was shown to be superior to antiplatelet therapy (odds ratio 0.37; 95\% CI: 0.23-0.60). The authors also demonstrated similar effectiveness of surgical closure to warfarin use (odds ratio 1.19; 95\% CI: 0.62-2.27). However, results of this meta-analysis need to be interpreted with caution as it was based on just a few studies, and it did not include device closure.

\section{Device Closure}

With the advent of modern intravascular procedures PFO closure became a very important and widely studied treatment option in prevention of cerebral ischemic events as well as in migraine prevention. Multiple studies of different design including randomized, non-randomized, retrospective and case-control ones have been published. These studies are based on different devices including Amplazer, CardioSeal, PFO-Star, etc. The frequency of residual RLS varied between 1 and $34 \%$ in different studies with different lengths of follow-up [62, 63]. There was one meta-analysis comparing older device closure trials with medical management. Khairy et al. [64] analyzed secondary stroke prevention studies in patients with a PFO that were published between 1985 and 2003. They included 10 studies of transcatheter closure (number of patients 1355) and 6 medical therapy studies (895 patients). The one-year incidence of recurrent cerebral ischemic events varied from 0 to $4.9 \%$ in device closure groups versus $3.8-12 \%$ in medically treated ones. The frequency of periprocedural complications ranged from 1.5 to $7.9 \%$ (major and minor, respectively). These data should be approached with great caution as studies included in this analysis were very heterogeneous as far as data, definitions, intensity of follow-up, baseline characteristics of studied populations and distribution of risk factors are concerned.

Very recently, results of two large-scale trials have been published. Whorle et al. [65] studied Premere ${ }^{\mathrm{TM}}$ PFO closure device. This was a prospective observational registry of patients with a history of stroke or transient ischemic attack and confirmed RLS through a PFO. In total, there were 267 patients were included. The frequency of residual shunting was $16.8,5.6$ and $6.5 \%$ for small, moderate and large shunts (total of $28.9 \%$ ). After device implantation, patients were treated medically in a noncontrolled way according to common clinical practice. Overall, the use of anticoagulants decreased after the closure (from 27 to 3\%) and the use of antiplatelets increased (aspirin from 64 to $95 \%$, thienopyridines from 27 to $80 \%)$. After a mean fol- low-up of $11 \pm 9$ months, there was no stroke or transient ischemic attack recurrence. There were 5 patients with new-onset atrial fibrillation (1.9\%), and one patient with thrombophilic diathesis developed thrombosis. Results of this registry are interesting, but should be interpreted with caution due to its non-randomized design.

CLOSURE-1 was one of the biggest studies performed so far. This was a randomized open-label trial on the effectiveness of PFO closure versus medical management in patients aged 18-60 with a PFO and a history of a cryptogenic cerebral event such as stroke or transient ischemic attack. The primary end point was composed of stroke, transient ischemic attack during 2 years' followup, any cause of death during the first 30 days and death from neurological causes between 31 days and 2 years. In total, 909 patients were enrolled into this trial. The incidence of the primary end point was similar in both groups (5.5\% in device closure and $6.8 \%$ in medically treated; adjusted hazard ratio 0.78 ; $95 \%$ CI: $0.45-1.35$ ). The rates for stroke were 2.9 vs. $3.1 \%$ in device versus medically treated, and for transient ischemic attack, they were 3.1 versus $4.1 \%$, respectively $(p=0.44)$. As far as safety is concerned, there were no deaths within the first 30 days and also up to 2 years' follow-up [66]. Results of this large scale trial show that there is no difference between device closure and medical management in secondary stroke prevention in patients with a PFO.

Wahl et al. [67] have just published results of a longterm follow-up propensity score-matched study on a moderately low number of patients. Patients were offered secondary stroke prevention either with PFO closure $(n=150)$ or best medical management $(n=158)$. The outcome measured in this study was a composite of stroke, transient ischemic attack or peripheral embolism. In total, 103 propensity score-matched patients were assessed (median follow-up of 9 years). The closure group showed better results as far as primary end point occurrence was concerned as there were $11 \%$ of events in closure versus $21 \%$ of events in the best medical treatment groups with the hazard ratio 0.43 (95\% CI: $0.20-0.94 ; \mathrm{p}=0.033$ ). Of note is the fact that that the main difference was shown for transient ischemic attack occurrence ( 5 vs. $14 \%$ respectively; hazard ratio $0.31 ; 0.1-0.94 ; \mathrm{p}=0.039$ ). The all cause and cardiovascular case fatality in both groups was similar (6 and 3\%, respectively). This study showed that in this particular subset of patients, PFO closure did better than medical management. However, due to the size of the sample and non-randomized design, these results may be added to the pool of evidence rather than being considered as practice changing. 
Last but not least is the recent completion of enrollment into the RESPECT trial (clinical trial identifier NCT00465270) as announced by the investigators (980 patients enrolled). This is a phase II, open label randomized trial investigating whether percutaneous PFO closure with the AMPLATZER PFO Occluder is superior to current standard of medical treatment in secondary prevention of embolic stroke. The primary outcome measure is the recurrence of non-fatal strokes [68]. Results of this study are to be presented by the end of this year according to the investigators.

There are a few ongoing trials that need to be quoted here. The Patent Foramen Ovale Closure or Anticoagulants Versus Antiplatelet Therapy to Prevent Stroke Recurrence (CLOSE; NCT00562289) is an open trial on the safety and efficacy of vitamin K antagonists (VKA) treatment (target INR 2-3) versus device closure in treatment of patients with ischemic stroke and a $\mathrm{PFO}+\mathrm{ASA}$. Aspirin is the active comparator arm in this trial. The primary outcome measure is the occurrence of stroke (fatal or not) during the 3-5 years' follow-up period [69]. Another study is the PC-Trial: (Patent Foramen Ovale and Cryptogenic Embolism; NCT00166257). The status of this study is active but not recruiting based on the available information. The aim of this study is to compare the efficacy of percutaneous closure of PFO with medical treatment in patients with cryptogenic embolism. This is an open-label randomized safety/efficacy trial. The patients are randomized to receive either the active comparator, which is the antithrombotic treatment selected by the investigator (anticoagulation with the target INR 2-3; aspirin $100-325 \mathrm{mg} /$ day or clopidogrel $75-150 \mathrm{mg} /$ day), versus device closure with Amplatzer ${ }^{\circledR}$ PFO Occluder. The primary outcome measures are length of time before death, nonfatal cerebrovascular event and peripheral embolism [70]. The Gore REDUCE Clinical Study (GORE HELEX $^{\mathrm{TM}}$ Septal Occluder for Patent Foramen Ovale Closure in Stroke Patients; NCT00738894) is an active and currently recruiting randomized trial that compares the efficacy and safety of device closure of a PFO with concomitant aspirin use in recurrent stroke prevention versus aspirin alone. The primary outcome measure is freedom from recurrent ischemic stroke or imaging-confirmed TIA during 24 months of follow-up [71]. Once results of the active studies are available, they may be adding to the growing pool of data on PFO closure, which may eventually lead to a meta-analysis.

Stroke and Patent Foramen Ovale in Young Individuals

\section{International Guidelines on Management of Stroke in Young Patients with PFO}

The currently available information on the role of the RLS through the PFO in the pathogenesis of stroke in young individuals first of all does not provide any unequivocal data on the causality of PFO in stroke. This is why, given our current state of knowledge, any interventional procedures aiming at PFO closure should be considered only within well-designed randomized trials. There are currently several international and national guidelines on stroke prevention in patients with PFO. The American Academy of Neurology practice parameters literally say that PFO is NOT associated with risk of stroke and death in medically treated patients with cryptogenic stroke, but there is a possibility of increased risk of stroke in those with PFO+ASA. At this stage, there is no evidence favoring anticoagulants over aspirin, and there is insufficient evidence on the efficacy of interventional PFO closure [72].

European Stroke Organization guidelines suggest that endovascular closure of a PFO in stroke prevention is feasible and potentially offers some superiority over medical therapy; however, randomized trials are needed to confirm this [73]. We can find the same advice in the $\mathrm{Na}-$ tional Institute for Clinical Excellence guide [74]. In the most recently updated guidelines of the American College of Chest Physicians concerning patients with cryptogenic stroke and PRO or ASA, aspirin $50-100 \mathrm{mg} /$ day is recommended in secondary prevention. In those with cryptogenic stroke and PFO or ASA with recurrent events despite aspirin treatment VKA are recommended with a target INR of 2.5 (range 2.0-3.0) and device closure is suggested in preference to no VKA or aspirin therapy [75].

In summary, we can say that at this stage secondary stroke prevention after initial ischemic event in young patients with a PFO and or ASA should be based on medical treatment. There is not enough evidence to support the mechanical importance of RLS through the PFO in pathogenesis of stroke to support mechanical closure surgical or device. Surgical closure requires a major procedure, and long-term results vary between centers as far as residual shunts, periprocedural risks and long-term effectiveness are concerned. The body of evidence for device closure of the $\mathrm{PFO}$ is growing with regard to prevention of recurrent ischemic events. Further studies are needed to test this association, especially in connection with medical failure of secondary stroke prevention and more preselected subgroups of stroke survivors. More-

Eur Neurol 2013;69:108-117 
over, other hypothesis on the link between RLS through the PFO should be investigated including metabolic shunting and endothelial dysfunction. Joining PFO registers should be stimulated as large samples and prospective design of unbiased epidemiological studies can ascertain a common denominator for all therapeutic measures to be developed in individuals with a PFO and stroke risk. However, in clinical practice when facing a young patient with recurrent ischemic stroke (i.e. after a second event) on medical treatment, with massive RLS, presence of ASA and lack of other risk factors despite indepth investigations, a decision for PFO closure can be considered as a rescue. This decision should be made by a multidisciplinary team including a stroke neurologist and a cardiologist. The procedure should be done in an experienced center, preferably a center that has participated in relevant device closure trials.

\section{References}

1 Moorman A, Webb S, Brown NA, Lamers W, Anderson RH: Development of the heart. 1 . Formation of the cardiac chambers and arterial trunks. Heart 2003;89:806-814.

-2 Anderson RH, Webb S, Brown NA, Lamers W, Moorman A: Development of the heart. 2. Septation of the atriums and ventricles. Heart 2003;89:949-958.

- 3 Kiserud T: Fetal venous circulation - an update on hemodynamics. J Perinat Med 2000; 28:90-96.

-4 Anderson RH, Webb S, Brown NA, Lamers W, Moorman A: Development of the heart. 2. Septation of the atriums and ventricles. Heart 2003;89:949-958.

5 Rasanen J, Wood DC, Weiner S, Ludomirski A, Huhta JC: Role of the pulmonary circulation in the distribution of human fetal cardiac output during the second half of pregnancy. Circulation 1996;94:1068-1073.

-6 Kerut EK, Norfleet WT, Plotnick GD, Giles TD: Patent foramen ovale: a review of associated conditions and the impact of physiological size. J Am Coll Cardiol 2001;38:613-623.

7 Thompson T, Evans W: Paradoxical embolism. Q J Med 1930;23:135-152.

-8 Hagen PT, Scholz DG, Edwards WD: Incidence and size of patent foramen ovale during the first 10 decades of life: an autopsy study of 965 normal hearts. Mayo Clin Proc 1984;59:17-20.

-9 Fisher DC, Fisher EA, Budd JH, Rosen SE, Goldman ME: The incidence of patent foramen ovale in 1,000 consecutive patients. A contrast transesophageal echocardiography study. Chest 1995;107:1504-1509.

10 Meissner I, Whisnant JP, Khandheria BK, et al: Prevalence of potential risk factors for stroke assessed by transesophageal echocardiography and carotid ultrasonography: the SPARC study. Stroke Prevention: Assessment of Risk in a Community. Mayo Clin Proc 1999;74:862-869.

- 11 Hanley PC, Tajik AJ, Hynes JK, Edwards WD, Reeder GS, Hagler DJ, Seward JB: Diagnosis and classification of atrial septal aneurysm by two-dimensional echocardiography: report of 80 consecutive cases. J Am Coll Cardiol 1985;6:1370-1382.

12 Agmon Y, Khandheria BK, Meissner I, Gentile F, Whisnant JP, Sicks JD, O'Fallon MW, Covalt JL, Wiebers DO, Seward JB: Frequen- cy of atrial septal aneurysms in patients with cerebral ischemic events. Circulation 1999; 99:1942-1944.

13 Eustachius B: Opuscula Anatomica. Venice, Vincenzo Luchino, 1563.

14 Chiari H: Veber Netzbildungen im redden Vorhofe des Herzens. Beittr Path Anat 1897; 22:1-10.

15 Schneider B, Hofmann T, Justen MH, Meinertz T: Chiari's network: normal anatomic variant or risk factor for arterial embolic events? J Am Coll Cardiol 1995;26:203-210.

16 Edwards P, Wozniak M, Corretti M, Price TR: Cardiac Chiari network as an etiology for embolic stroke. J Stroke Cerebrovasc Dis 1994;4:238-241.

17 Ho SY, McCarthy KP, Rigby ML: Morphological features pertinent to interventional closure of patent oval foramen. J Interv Cardiol 2003;16:33-38.

18 Werner JA, Cheitlin MD, Gross BW, et al: Echocardiographic appearance of the Chiari network: differentiation from right-heart pathology. Circulation 1981;63:1104-1109.

19 Lechat P, Mas JL, Lascault G, Loron P, Theard M, Klimczac M, Dorobinski G, Thomas D, Grosgogeat Y: Prevalence of patent foramen ovale in patients with stroke. N Engl J Med 1988;318:1148-1152.

20 Overell JR, Bone I, Lees KR: Interatrialseptal abnormalities and stroke: a meta-analysis of case-control studies. Neurology 2000;55 $1172-1179$.

21 Di TM, Sacco RL, Gopal A, Mohr JP, Homma S: Patent foramen ovale as a risk factor for cryptogenic stroke. Ann Intern Med 1992; 117:461-465.

22 Mas JL, Arquizan C, Lamy C, et al: Recurrent cerebrovascular events associated with patent foramen ovale, atrial septal aneurysm, or both. N Engl J Med 2001;345:1740-1746.

23 Moon RE, Camporesi EM, Kisslo JA: Patent foramen ovale and decompression sickness in divers. Lancet 1989;1:513-514.

24 Wilmshurst PT, Byrne JC, Webb-Peploe MM: Relation between interatrial shunts and decompression sickness in divers. Lancet 1989;2:1302-1306.

25 Kerut EK, Norfleet WT, Plotnick GD, Giles TD: Patent foramen ovale: a review of associated conditions and the impact of physiological size. J Am Coll Cardiol 2001;38:613-623.
6 Allemann Y, Hutter D, Lipp E, Sartori C, Duplain H, Egli M, Cook S, Scherrer U, Seiler C: Patent foramen ovale and high-altitude pulmonary edema. JAMA 2006;296:2954-2958.

27 Dear WE, Chen P, Barasch E, Anderson HV, Varughese AT, Macris MP: Sixty-eight-yearold woman with intermittent hypoxemia. Circulation 1995;91:2284-2289.

28 Kawamata T, Takeshita M, Ishizuka N, Hori $\mathrm{T}$ : Patent foramen ovale as a possible risk factor for cryptogenic brain abscess: report of two cases. Neurosurgery 2001;49:204-206.

29 Klotzsch C, Sliwka U, Berlit P, Noth J: An increased frequency of patent foramen ovale in patients with transient global amnesia. Analysis of 53 consecutive patients. Arch Neurol 1996;53:504-508.

30 Mori S, Sadoshima S, Tagawa K, Iino K, Fujishima M: Massive spinal cord infarction with multiple paradoxical embolism: a case report. Angiology 1993;44:251-256.

31 Chaikof EL, Campbell BE, Smith RB, III: Paradoxical embolism and acute arterial occlusion: rare or unsuspected? J Vasc Surg 1994;20:377-384.

-32 Carey HB, Boltax R, Dickey KW, Finkelstein FO: Bilateral renal infarction secondary to paradoxical embolism. Am J Kidney Dis 1999;34:752-755.

33 Agostoni P, Gasparini G, Destro G: Acute myocardial infarction probably caused by paradoxical embolus in a pregnant woman. Heart 2004;90:12e.

34 Koullias GJ, Elefteriades JA, Wu I, Jovin I, Jadbabaie F, McNamara R: Massive paradoxical embolism: caught in the act. Circulation 2004;109:3056-3057.

-35 Piechowski-Jozwiak B, Devuyst G, Bogousslavsky J: Migraine and patent foramen ovale: a residual coincidence or a pathophysiological intrigue? Cerebrovasc Dis 2006;22: 91-100.

-36 Lamy C, Giannesini C, Zuber M, et al: Clini$\mathrm{cal}$ and imaging findings in cryptogenic stroke patients with and without patent foramen ovale: the PFO-ASA Study. Atrial Septal Aneurysm. Stroke 2002;33:706-711.

37 Homma S, Sacco RL, Di Tullio MR, Sciacca RR, Mohr JP: Effect of medical treatment in stroke patients with patent foramen ovale: patent foramen ovale in Cryptogenic Stroke study. Circulation 2002;105:2625-2631. 
-38 Devuyst G, Despland PA, Bogousslavsky J, Jeanrenaud X: Complementarity of contrast transcranial Doppler and contrast transesophageal echocardiography for the detection of patent foramen ovale in stroke patients. Eur Neurol 1997;38:21-25.

-39 Job FP, Ringelstein EB, Grafen Y, et al: Comparison of transcranial contrast Doppler sonography and transesophageal contrast echocardiography for the detection of patent foramen ovale in young stroke patients. Am J Cardiol 1994;74:381-384.

-40 Steiner MM, Di Tullio MR, Rundek T, et al: Patent foramen ovale size and embolic brain imaging findings among patients with ischemic stroke. Stroke 1998;29:944-948.

-41 Stone DA, Godard J, Corretti MC, et al: Patent foramen ovale: association between the degree of shunt by contrast transesophageal echocardiography and the risk of future ischemic neurologic events. Am Heart J 1996;131:158-161.

42 Schuchlenz HW, Weihs W, Horner S, Quehenberger F: The association between the diameter of a patent foramen ovale and the risk of embolic cerebrovascular events. Am J Med 2000;109:456-462.

43 Knauth M, Ries S, Pohimann S, et al: Cohort study of multiple brain lesions in sport divers: role of a patent foramen ovale. BMJ 1997; 314:701-705.

44 Johnson BI: Paradoxical embolism. J Clin Pathol 1951;4:316-332.

-45 Zicari E, Tassi R, Stromillo ML, Pellegrini M, Bianchi S, Cevenini G, Gistri M, De Stefano N, Federico A, Dotti MT: Right-to-left shunt in CADASIL patients: prevalence and correlation with clinical and MRI findings. Stroke 2008;39:2155-2157.

-46 Niessen K, Karsan A: Notch signaling in the developing cardiovascular system. Am J Physiol Cell Physiol 2007;293:C1-C11.

-47 Karttunen V, Ventila M, Ikaheimo M Niemela M, Hillbom M: Ear oximetry: a noninvasive method for detection of patent foramen ovale: a study comparing dye dilution method and oximetry with contrast transesophageal echocardiography. Stroke 2001;32:448-453.

-48 Devuyst G, Piechowski-Jozwiak B, Karapanayiotides T, et al: Controlled contrast transcranial Doppler and arterial blood gas analysis to quantify shunt through patent foramen ovale. Stroke 2004;35:859-863.

-49 Pitt BR, Hammond GL, Gillis CN: Comparison of pulmonary and extrapulmonary extraction of biogenic amines. J Appl Physiol 1982;52:1545-1551.

-50 Piechowski-Jozwiak B, Devuyst G, Bogousslavsky J: Migraine and patent foramen ovale: a residual coincidence or a pathophysiological intrigue? Cerebrovasc Dis 2006;22: 91-100.

51 Gimmel'farb GN, Guliamov DS, Karimova TZ, Gerasimov NM: Vasoactive hormone metabolism in the lungs of patients with congenital heart defects (in Russian). Kardiologiia 1987;27:61-65.
52 Bogousslavsky J, Garazi S, Jeanrenaud X, Aebischer N, Van Melle G: Stroke recurrence in patients with patent foramen ovale: the Lausanne Study. Lausanne Stroke with Paradoxal Embolism Study Group. Neurology 1996;46:1301-1305.

53 Serena J, Marti-Fàbregas J, Santamarina E, Rodríguez JJ, Perez-Ayuso MJ, Masjuan J, Segura T, Gállego J, Dávalos A, CODICIA, Right-to-Left Shunt in Cryptogenic Stroke Study, Stroke Project of the Cerebrovascular Diseases Study Group, Spanish Society of Neurology: Recurrent stroke and massive right-to-left shunt: results from the prospective Spanish multicenter (CODICIA) study. Stroke 2008;39:3131-3136.

54 Fischer D, Gardiwal A, Haentjes J, Klein G, Meyer GP, Drexler H, Hausmann D, Schaefer A: Sustained risk of recurrent thromboembolic events in patients with patent foramen ovale and paradoxical embolism: long-term follow-up over more than 15 years. Clin Res Cardiol 2012;101:297-303.

55 Mohr JP, Thompson JL, Lazar RM, Levin B, Sacco RL, Furie KL, Kistler JP, Albers GW, Pettigrew LC, Adams HP Jr, Jackson CM, Pullicino P: A comparison of warfarin and aspirin for the prevention of recurrent ischemic stroke. N Engl J Med 2001;345:14441451.

56 Almekhlafi MA, Wilton SB, Rabi DM, Ghali WA, Lorenzetti DL, Hill MD: Recurrent cerebral ischemia in medically treated patent foramen ovale: a meta-analysis. Neurology 2009;73:89-97.

57 Ruchat P, Bogousslavsky J, Hurni M, Fischer AP, Jeanrenaud X, von Segesser LK: Systematic surgical closure of patent foramen ovale in selected patients with cerebrovascular events due to paradoxical embolism. Early results of a preliminary study. Eur J Cardiothorac Surg 1997;11:824-827.

58 Devuyst G, Bogousslavsky J, Ruchat P, Jeanrenaud X, Despland PA, Regli F, Aebischer N, Karpuz HM, Castillo V, Guffi M, Sadeghi H: Prognosis after stroke followed by surgical closure of patent foramen ovale: a prospective follow-up study with brain MRI and simultaneous transesophageal and transcranial Doppler ultrasound. Neurology 1996; 47:1162-1166

59 Homma S, Di Tulio MR, Sacco RL, Sciacca RR, Smith C, Mohr JP: Surgical closure of patent foramen ovale in cryptogenic stroke patients. Stroke 1997;28:2376-2381.

60 Dearani JA, Ugurlu BS, Danielson GK, Daly RC, McGregor CG, Mullany CJ, Puga FJ, Orszulak TA, Anderson BJ, Brown RD, Schaff HV: Surgical patent foramen ovale closure for prevention of paradoxical embolism-related cerebrovascular ischemic events. Circulation 1999;100(suppl 19): II171-II175.

61 Orgera MA, O’Malley PG, Taylor AJ: Secondary prevention of cerebral ischemia in patent foramen ovale: systematic review and meta-analysis. South Med J 2001;94:699703.
62 Braun MU, Fassbender D, Schoen SP, Haass M, Schraeder R, Scholtz W, Strasser RH: Transcatheter closure of patent foramen ovale in patients with cerebral ischemia. J Am Coll Cardiol 2002;39:2019-2025.

63 Martin F, Sanchez PL, Doherty E, ColonHernandez PJ, Delgado G, Inglessis I, Scott $\mathrm{N}$, Hung J, King ME, Buonanno F, Demirjian Z, de Moor M, Palacios IF: Percutaneous transcatheter closure of patent foramen ovale in patients with paradoxical embolism. Circulation 2002;106:1121-1126.

64 Khairy P, O’Donnell CP, Landzberg MJ: Transcatheter closure versus medical therapy of patent foramen ovale and presumed paradoxical thromboemboli: a systematic review. Ann Intern Med 2003;139:753-760.

65 Whorle J, Bertrand B, Sondergaard L, Turner M, Scholtz W, Ibrahim R, Bourlon F: PFO closuRE and CryptogenIc StrokE (PRECISE) registry: a multi-center, international registry. Clin Res Cardiol 2012;101:787-793.

-66 Furlan AJ, Reisman M, Massaro J, Mauri L, Adams H, Albers GW, Felberg R, Herrmann H, Kar S, Landzberg M, Raizner A, Wechsler L: Closure or medical therapy for cryptogenic stroke with patent foramen ovale. $\mathrm{N}$ Engl J Med 2012;366:991-999.

67 Wahl A, Jüni P, Mono M, Kalesan B, Praz F, Geister L, Räber L, Nedeltchev K, Mattle H, Windecker S, Meier B: Long-term propensity score-matched comparison of percutaneous closure of patent foramen ovale with medical treatment after paradoxical embolism. Circulation 2012;125:803-812.

$68 \mathrm{http}: / / \mathrm{www}$.clinicaltrials.gov/ct2/show/NC T00465270? term =RESPECT+AND+PFO\& $\mathrm{r}$ ank=1.

$69 \mathrm{http} / /$ www.clinicaltrials.gov/ct2/show/ NCT00562289?term=CLOSE\&rank $=2$.

$70 \mathrm{http} / / / \mathrm{www} . c l i n i c a l t r i a l s . g o v / \mathrm{ct} 2 /$ show/ NCT00166257?term=PC-trial\&rank=1.

$71 \mathrm{http}: / / \mathrm{ww} w . c l i n i c a l t r i a l s . g o v / \mathrm{ct} 2 /$ show/NC T00738894? term=REDUCE+PFO\&rank=1.

72 Messé SR, Silverman IE, Kizer JR, Homma S, Zahn C, Gronseth G, Kasner SE, Quality Standards Subcommittee of the American Academy of Neurology: Practice parameter: recurrent stroke with patent foramen ovale and atrial septal aneurysm: report of the Quality Standards Subcommittee of the American Academy of Neurology. Neurology 2004;62:1042-1050.

$73 \mathrm{http}: / /$ www.eso-stroke.org/pdf/ESO $\% 20$ Guidelines_update_Jan_2009.pdf.

74 http://www.nice.org.uk/nicemedia/live/ 11140/31253/31253.pdf.

75 Guyatt GH, Akl EA, Crowther M, Gutterman DD, Schuünemann HJ, American College of Chest Physicians Antithrombotic Therapy and Prevention of Thrombosis Panel: Executive summary: Antithrombotic Therapy and Prevention of Thrombosis, 9th ed: American College of Chest Physicians Evidence-Based Clinical Practice Guidelines. Chest 2012;141(suppl 2):7S-47S. 